\title{
Cutaneous induction of breathing in perinatal rats
}

\author{
APRIL E. RONCA and JEFFREY R. ALBERTS \\ Indiana University, Bloomington, Indiana
}

\begin{abstract}
We tested the hypothesis that cutaneous stimulation present during perinatal life induces and maintains breathing in fetal and neonatal rats. Late-gestation (Day 21) rat fetuses with intact umbilical connections were externalized from the uterus of a spinally transected dam. In the first experiment, fetuses were externalized into air heated to intrauterine temperature $\left(37.5^{\circ} \mathrm{C}\right)$ and were either stroked with a brush for 2 min to mimic the dam's postpartum licking or not stroked. The single episode of stimulation more than doubled fetal breathing rates for the duration of a 1-h test, demonstrating facilitative effects of cutaneous stimulation on perinatal respiratory behavior. In the second experiment, we investigated the effects of simulated maternal licking on pups' postpartum breathing rates. Fetuses were exposed to a regime mimicking birth in which the amniotic sac was removed, the fetus was exposed to postpartum nest temperature $\left(26^{\circ} \mathrm{C}\right)$, and its umbilical cord was occluded. Subjects were then exposed to (1) brush stroking, to mimic maternal licking at birth; (2) body compression, to simulate effects of uterine contractions during labor; (3) body compression followed by stroking; or (4) neither compression nor stroking. Compressed and/or stroked pups showed similar, rapid respiratory rates. Most of the noncompressed, nonstroked controls did not; only $25 \%$ of the nonstimulated pups were respiring at the end of the test. The third experiment addressed potential confounds which might arise from the fetuses' exposure to anesthesia prior to respiratory measurements. Fetuses delivered by cesarean section without anesthesia were either stroked or remained undisturbed. Pups in a vaginal delivery control group were removed from the nest after 2 min of postpartum licking by the dam. All of the stroked and vaginally delivered pups were respiring after $1 \mathrm{~h}$, in contrast to $25 \%$ of the nonstroked controls. Together, these results suggest that cutaneous stimulation, delivered in amounts that approximate biological values, provides a powerful stimulus to perinatal respiratory behavior. In conjunction with previous work, these findings support the view that fetal sensory experience plays an important role in mediating the cascade of adaptive adjustments required for the transition from fetus to newborn.
\end{abstract}

The movement of air in and out of the lungs is accomplished by the contraction of voluntary muscles (Lambertson, 1974). Breathing movements begin during prenatal life (Dawes, 1974), at which time lung fluid, rather than air, is moved through the trachea (Olver, 1981). Although unrelated to gas-exchange functions, prenatal respiratory movements are thought to contribute to the remarkable postnatal ability of the respiratory musculature to maintain vigorous, continuous, coordinated function after birth (Dawes, 1968; Liggins, 1982). Numerous factors have been hypothesized to trigger the onset of continuous breathing at birth, including hyperoxia (Baier et al., 1992), umbilical cord occlusion (Adamson, Kuipers, \& Olsen, 1991; Baier et al., 1992), cutaneous cooling (Gluckman, Gunn, \& Johnston, 1983), and somatic stimulation (Ronca \& Alberts, 1995b; Scarpelli, Condorelli, \& Cosmi, 1977).

The habitat of the mammalian fetus and newborn contains significant amounts of afferent input (Fifer \& Moon,

This research was supported by National Institute of Mental Health Grant MH46485 to A.E.R. and J.R.A. The authors would like to thank Carrie Iwema and Michael Armbruster for technical assistance. Correspondence and reprint requests should be addressed to $\mathrm{A}$. E. Ronca, Dept. of Psychology, Indiana University, Bloomington, IN 47405 (email: ronca@psythird.psych.indiana.edu).
1988; Gerhardt, 1989; Hofer, 1981; Narayanan, Fox, \& Hamburger, 1971; Ronca, Lamkin, \& Alberts, 1993; Schaal \& Orgeur, 1992; Vince, Billing, Baldwin, Toner, $\&$ Weller, 1985). Around the time of birth, the fetus is exposed to compression, cooling, painful stimuli, increased gravitational forces, and cutaneous stimuli. Many stimuli which comprise the perinatal sensory environment are present at levels that are detectable to the mammalian perinate (Bradley \& Mistretta, 1975; Decasper \& Fifer, 1980; Ronca \& Alberts, 1994; Vince et al., 1985) and play key roles in perinatal sensory experience and postpartum adaptation (Alberts \& Ronca, 1993; Ronca \& Alberts, 1995a ).

Sensory experience associated with birth may also contribute to the organization of postpartum behavior. During parturition, the fetus experiences repeated, strong uterine contractions, extrusion through the birth canal, and abrupt exposure to a cold postpartum environment (Ronca et al., 1993). In a previous study, we presented fetal and neonatal rats with separate components of the birth process (Ronca \& Alberts, 1995b) and found that compression, but not cooling to nest temperature or umbilical-cord occlusion, significantly increased fetal breathing rate. In contrast, umbilical-cord occlusion alone produced a high attrition rate. Compression combined with umbilical-cord occlusion ameliorated this out- 
come, and was necessary for producing postpartum respiratory rates characteristic of vaginally delivered animals.

Compression exerts both sensory (cutaneous) and nonsensory (mechanical) effects on offspring, either one or both of which might account for the transition to postnatal respiratory behavior. The purpose of the present study was to examine the role of cutaneous stimuli in the production of perinatal respiratory behavior and postpartum survival. In this investigation, we used a biologically derived stimulus, namely the stroking of pups' body surface to mimic postpartum licking by the dam. In Experiment 1, we examined the effects of cutaneous stimulation on the respiratory rate of late-gestation rat fetuses. In Experiment 2, we investigated the induction of postpartum respiratory behavior and compared effects of stroking with those of simulated uterine contractions. In Experiment 3, we examined the effects of stroking on postpartum survival of pups delivered by cesarean section (without anesthesia), in order to address the possibility that our results might be due to respiratory depression associated with fetuses' exposure to anesthesia.

\section{EXPERIMENT 1 \\ Cutaneous Effects on Fetal Respiratory Behavior}

Condorelli and Scarpelli (1975) demonstrated a somaticrespiratory reflex in the mature sheep fetus: electrical stimulation of sciatic nerve afferents elicited breathing movements. In $66 \%$ of the cases, the respiratory response outlived the stimulus. In a subsequent study, fetuses presented with $30 \mathrm{sec}$ of vibration, rubbing, or scratching of the hindlimb responded with short-lived bursts of respiratory activity (Scarpelli et al., 1977). While these observations suggest somatosensory activation or recruitment of the neural substrates of respiration, they reveal little about the role of cutaneous stimulation in the generation of perinatal breathing under ordinary circumstances. Ewes (and therefore fetuses) were tested under general thiopental anesthesia, so the amount of afferent stimulation available to fetuses was not typical of natural uterine or postpartum conditions.

In this experiment, we investigated the possibility that biologically typical stimulation can induce fetal respiratory behavior. Brush stroking was used to simulate the cutaneous effects of the dam's postpartum licking. (For other studies in which brush stroking has been used to mimic such maternal stimulation of rat pups, see Alberts \& May, 1980; Evoniuk, Kuhn, \& Schanberg, 1979; Kuhn, Butler, \& Schanberg, 1978; Kuhn et al., 1991; Pederson \& Blass, 1982; Sullivan \& Hall, 1988; Sullivan, Shokrai, \& Leon, 1988; Sullivan, Wilson, \& Leon, 1988.) Stimulus parameters were selected from previous descriptive and quantitative studies of maternal behavior of the rat during pregnancy and parturition (Ronca et al., 1993; Rosenblatt \& Lehrman, 1967). Inasmuch as Alberts and May (1980) found that brush stroking stimulated respiratory behavior in 1-day-old rat pups, we expected an augmentation of fetal respiratory rate. Fetuses were externalized from the uterus with intact umbilical connections to the dam, thereby preserving ongoing gas-exchange functions. To avoid potential confounding effects of labor contractions on respiratory behavior, testing was conducted on the day prior to birth.

\section{Method}

\section{Subjects}

A total of 18 rat fetuses were the subjects used in this experiment. The subjects were the offspring of time-mated SpragueDawley rats bred in the Indiana University colony. Pregnant dams were housed in standard polyurethane tubs in a colony room maintained at a constant temperature of $23^{\circ} \mathrm{C}$, under a 16:8-h light:dark cycle. Purina Rat Chow and water were available ad lib. Vaginal cytology was examined each day of the breeding period to determine the date of conception. The first day on which sperm were observed was designated Gestational Day 0 (GD0) of the 22-day gestational period. All procedures followed standards for animal care and use prescribed by the National Institutes of Health and Indiana University. A single rat fetus was tested from each litter.

\section{Apparatus}

For testing, the subject fetus was positioned in a rubber-lined egg-shaped cup $(3 \times 6 \mathrm{~cm})$ fitted with a notch $(3-\mathrm{cm}$ diam $)$ cut into one side to accommodate the fetus's umbilical-placental attachment to the uterus. The cup was attached to a microscope stand that provided fine control over the fetus's vertical position above the uterus. (This device is illustrated elsewhere in Ronca \& Alberts, 1994.) Air temperature was maintained at intrauterine temperature $\left(37.5^{\circ} \pm .5^{\circ} \mathrm{C}\right)$ by housing the unit within a modified glove-box incubator with a Plexiglas hood. A camera (Sony Model DXC-107) with a high-resolution lens (Schneider-Kreuznach Cinegon $1: 1.8 / 10$ ) was attached to the hood and positioned to view the fetus within the egg-shaped cup from above. The camera was fed into a VCR (Gyyr Model TLC-1400) with a built-in time base ( $1-\mathrm{sec}$ resolution), and the image was continuously displayed on a closed-circuit monitor.

\section{Treatment of the Dam}

Established procedures for fetal observation in rats (Narayanan et al., 1971; Smotherman, Richards, \& Robinson, 1984) were used to test the subjects. Briefly, a GD21 pregnant dam was anesthetized with methoxyflurane (Metofane, Pittman-Moore), then spinally transected via chemomyelotomy $(100 \mu 1$ of $100 \%$ ethanol administered between the first and second lumbar vertebrae). This procedure blocks sensation and voluntary movement in the lower body. The dam was then placed in a Plexiglas chair, her lower body immersed in heated Ringer's solution $\left(37.5^{\circ} \pm .5^{\circ} \mathrm{C}\right)$, and a laparotomy was performed. To avoid residual effects of general anesthesia on fetal subjects, the onset of observation was delayed for $20 \mathrm{~min}$ following surgical manipulation of the dam. Fetuses are behaviorally active and responsive to stimulation following this procedure (Ronca \& Alberts, 1994, 1995b). Upon the completion of testing, the dam and offspring were euthanized with $\mathrm{CO}_{2}$.

\section{Test Procedure}

A midline incision was made between the inguinal nipple pairs, and both uterine horns were gently externalized into the heated bath. The temperature of the air above the bath was precisely controlled at $37.5^{\circ} \pm 0.5^{\circ} \mathrm{C}$, using the incubator and hood assembly described earlier. The mother's head and upper body were recessed through the hood into room air (maintained at approximately $22^{\circ} \mathrm{C}$ ) to protect her body temperature. Testing of subjects was randomized across left and right horns. The uterine wall of the designated horn was incised (approximately $1.5 \mathrm{~cm}$ ) along the antimesometrial border between the first and second fetus proximal to the ovary. The fetus in the second uterine position was externalized from the horn and elevated slightly above the uterus to prevent di- 
rect exposure of the mouth and nares to the bath. Using a microforceps, the fetal membranes were gently removed from the head and body and the fetus was positioned in the egg cup. To protect the umbilical attachment, the egg cup containing the test fetus was kept in close proximity to the uterus for the duration of the test. The cup also buffered the subject from activity of the dam and siblings during the test, and provided a stationary platform that facilitated collection of high-quality videorecords for data analysis.

\section{Experimental Conditions}

Subjects were assigned to one of two conditions. In the stroke condition (STR), fetuses received 2 min of stroking across the body surface using a commercial foam paintbrush ( 1 in. wide) dampened with heated saline. Stroking consisted of rapid, short, back-and-forth sweeps applied randomly across the entire body surface. Care was taken to stimulate the dermal surface without applying deep pressure to the pup's skeleton or musculature. Fetuses in the control condition (CNTL) were treated identically to those in the STR condition except that no st roking was applied. To avoid uncontrolled stimulation that might evoke respiratory behavior, the handling of fetuses was minimal and necessary handling was performed gently.

\section{Data Analysis}

Using a microprocessor-based system, individual respiratory movements were encoded during playback of the videotapes, which provided clear, close-range images of the pups from which breathing movements could be reliably identified. Respiratory movements consisted of either gasps or rhythmic breaths (Ronca \& Alberts, 1995b). Gasps consisted of deep inspirations accompanied by mouth opening and chest expansion, while rhythmic breaths were rapid, regular, and shallow, identified predominantly by thoracic movement. Both categories of respiratory behavior were quantifiable with an interrater reliability of $R>.93$.

For each fetus, number of respirations were counted for consecutive 10-min bins across the $1-\mathrm{h}$ test and expressed as "breaths per minute" prior to the averaging of group data.

\section{Results and Discussion}

Some respiratory behavior was observed in both subject groups, but fetuses in the STR condition reached a greater than threefold elevation in overall respiratory rate as compared with that of fetuses in the CNTL condition (total respiratory frequency: STR, $662 \pm 176 S E$; CNTL, $204 \pm 42 S E$ ).

Figure 1 shows the average number of breaths per minute during the 1-h test for each experimental condition. Overall respiratory rates of fetuses were significantly higher in the STR condition than in the CNTL condition [ANOVA, $F(1,16)=6.0, p<.05$ ]. For both subject groups, average respiratory rate remained stable across the 1 -h test [ANOVA, $F(5,80)=1.0$, n.s.], with no interaction between groups $(F<1.0)$.

Although stimulation was applied for only $2 \mathrm{~min}$ following externalization of the fetus into the heated air environment, the facilitatory effect of the single stimulation episode persisted across the 1-h test. Importantly, the average number of respirations emitted by fetal rats in this study was similar to the number observed in our previous study, in which fetal rats were exposed to simulated uterine contractions (662 vs. 608 ; see Ronca \& Alberts, 1995b). These results indicate that cutaneous stimulation effectively induces respiratory behavior in

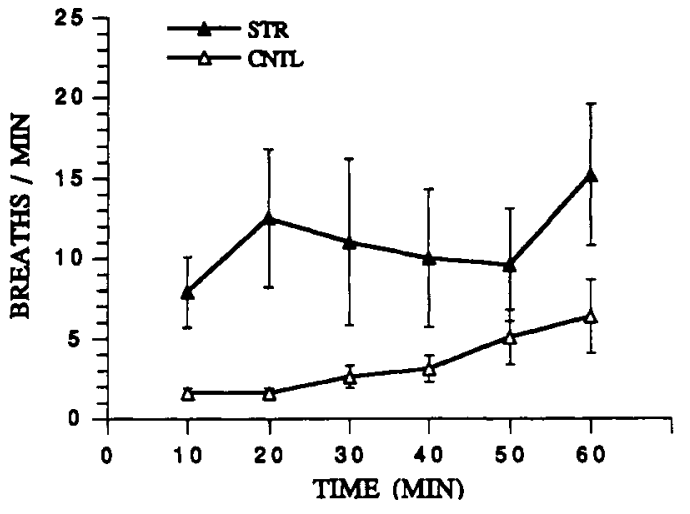

Figure 1. The average number of breaths per minute $( \pm S E$ ) for stroke (STR) and control (CNTL) fetuses during a 1-h test $(n=9$ per condition).

fetal rats, and that effects of this cutaneous stimulus on fetal breathing rate are comparable to those induced by simulated uterine contractions.

Cutaneous stimulation, presented at levels approximating those which normally occur within the postpartum nest, is within sensory detection ranges of fetal rats, as evidenced by the appearance of heart rate (HR) and motor responses to stimulation (Ronca \& Alberts, 1994; Ronca, Smotherman, Robinson, \& Alberts, 1987; Smotherman $\&$ Robinson, 1988). The present results indicate that cutaneous stimulation is also a sufficient stimulus for the induction of fetal breathing. In addition, the facilitatory effect was long-lived, causing increased fetal respiratory behavior for the duration of the $1-\mathrm{h}$ measurement interval. Stimulation from the dam appears to be critical for inducing and regulating basic biological functions in neonates (Evoniuk et al., 1979; Hofer, 1983; Hofer \& Shair, 1982; Hofer \& Winer, 1975; Kuhn et al., 1978; Shear, Brunelli, \& Hofer, 1983; Smotherman, 1983; Stanton \& Levine, 1984), independent of nutritional variables (Hofer, 1983; Hofer \& Shair, 1982; Hofer \& Winer, 1975). The findings of Experiment 1 suggest another important regulatory role for postpartum maternal care, namely, the initiation of sustained breathing at birth. In Experiment 2, we tested this hypothesis.

\section{EXPERIMENT 2 Cutaneous Effects on Newborn Respiratory Behavior}

Fetal rats experience partus in the form of compressions from uterine contractions and passage through the birth canal, cooling from exposure to the extrauterine milieu, and cutaneous stimulation from maternal licking.

We previously measured breathing movements in perinatal rats exposed to separate components of the birth process, and found that pups exposed to compression showed high rates of breathing as compared with those of pups exposed to postpartum nest temperature $\left(22^{\circ} \mathrm{C}\right)$ or heated air $\left(37.5^{\circ} \mathrm{C}\right.$; Ronca \& Alberts, $\left.1995 \mathrm{~b}\right)$. Seventy-seven percent of pups exposed to umbilical- 
cord occlusion alone showed rapid postpartum demise, an effect that was reversed by compressive stimulation but not by exposure to the thermal effects of birth.

Experiment 2 was conducted to evaluate whether cutaneous stimulation would be sufficient to facilitate respiratory movements in the perinatal rat as well.

\section{Method}

\section{Subjects}

A total of 36 rat fetuses were used as subjects. Breeding, maintenance, and subject selection were as described in Experiment 1.

\section{General Procedure}

The procedure described in Experiment 1 was modified and used here. Dams were prepared for fetal testing, and the uterine horns were externalized into the heated Ringer's solution bath as described above. All subjects remained in utero, suspended on a platform within the waterbath for the first $15 \mathrm{~min}$ of the test. An incision was made in the antimesometrial border of the uterus, and the fetus in the second uterine position was deposited into the eggshaped cup. The cup was raised into the air above the bath, as described in Experiment 1, where the air temperature was maintained at $26^{\circ} \pm 0.5^{\circ} \mathrm{C}$ to mimic the temperature of the postpartum nest. Then the fetus's umbilical blood supply was interrupted via application of a microvascular clamp to the umbilical cord, the cord was cut proximal to the placenta, and the dam was removed and euthanized with $\mathrm{CO}_{2}$. The microvascular clamp remained in place for the duration of the test.

The subjects were assigned to one of four experimental conditions: (1) the compression condition (COMP, $n=8$ ), in which the target fetus's body was compressed through the uterine wall (described below); (2) the stroke condition (STR, $n=8$ ), in which brush stroking was applied to the fetus within the egg-shaped cup; (3) the compression/stroke condition (COMP/STR, $n=8$ ), in which body compression was applied to the fetus in utero, followed by stroking of the fetus within the egg-shaped cup; and (4) the control condition (CNTL), in which subjects were treated identically to the other groups except that they were neither compressed nor stroked (CNTL, $n=12$ ). After completion of the experimental manipulations, the subjects were videotaped for $1 \mathrm{~h}$ and respiratory frequency was measured during tape playback, as described in Experiment 1. At the completion of testing, the pups were euthanized with $\mathrm{CO}_{2}$.

\section{Stimuli}

Compression to mimic uterine contractions. Mechanical compression mimicking labor contractions was applied to the subject fetus in utero. Compression was produced with a latex balloon attached to a gram scale. The balloon-scale assembly was calibrated to deliver $15 \mathrm{~mm} \mathrm{Hg}$ pressure (for additional detail, see Ronca \& Alberts, 1994). Fifteen compressions, presented for $20 \mathrm{sec}$ each at the rate of $1 / \mathrm{min}$, were administered to each subject fetus. These values were derived from studies of intrauterine pressure (IUP) during labor in the rat (Fuchs, 1969, 1979; Ronca et al., 1993).

Brush stroking to mimic maternal postpartum licking of pups. Stroking was applied to each subject as described in Experiment 1.

\section{Results and Discussion}

For each group, breathing rates were observed following disconnection of the umbilical blood supply, a manipulation that required pups to initiate pulmonary respiration for survival. Pups in each condition respired during the $1-h$ test. Overall respiratory rates for the four groups were $(X \pm S D)$ : (1) STR, $1,040 \pm 597$, (2) COMP, $1,432 \pm 742$, (3) COMP/STR, $1,475 \pm 662$, and (4) CNTL,
$152 \pm 306$. Importantly, only 3 of the 12 CNTL subjects $(25 \%)$ continued to respire after the 40th minute of the test; in the other conditions, $100 \%$ of the subjects continued to respire for the entire test duration. For purposes of data analysis, zero was considered to be a valid numerical assignment for pups that did not respire during a 10 -min bin. Analysis of variance revealed a significant effect of condition $[F(3,35)=11.9, p<.01]$, with the STR, COMP, and COMP/STR conditions differing significantly from the CNTL condition but not from one another (Scheffé, $p<.05$ ).

Figure 2 illustrates breaths per minute taken at 10min intervals over the first postpartum hour for subjects in each experimental condition. Analysis of variance revealed a significant effect of time bin $[F(5,160)=36.6$, $p<.01]$ and a significant interaction $[F(15,160)=5.7$, $p<.01]$. Post hoc analysis revealed that the compressed groups differed from the CNTL group at each measurement interval [Scheffé, $p<.05$ ]. Subjects breathed at significantly higher rates in the COMP/STR condition than in the STR condition during the first measurement interval but not thereafter (Scheffé, $p<.05$ ). Pups in the STR condition respired at rates similar to those in the CNTL condition up to the 40th minute of the test (Scheffé, n.s.). The average respiratory rates of the three CNTL pups that were respiring at the end of $1 \mathrm{~h}$ were as follows $(M \pm S D): 10 \mathrm{~min}, 0 \pm 0 ; 20 \mathrm{~min}, 2 \pm 3 ; 30 \mathrm{~min}, 6 \pm 3$; $40 \mathrm{~min}, 9 \pm 2 ; 50 \mathrm{~min}, 19 \pm 16 ; 60 \mathrm{~min}, 22 \pm 22$.

Taken together, these findings support several conclusions. First, breathing increased significantly over the first postpartum hour for fetuses in all conditions except the CNTL condition. Seventy-five percent of the CNTL pups ceased respiring before completion of the test. These findings replicate our earlier work, in which $77 \%$ of noncompressed pups stopped respiring within $1 \mathrm{~h}$. The results of the present study permit expansion of our earlier conclusion: mechanical and/or cutaneous stimulation are critical for the induction of continuous postpartum respiratory behavior in rats. Second, overall respiration rates of pups receiving either mechanical or tactile stimulation

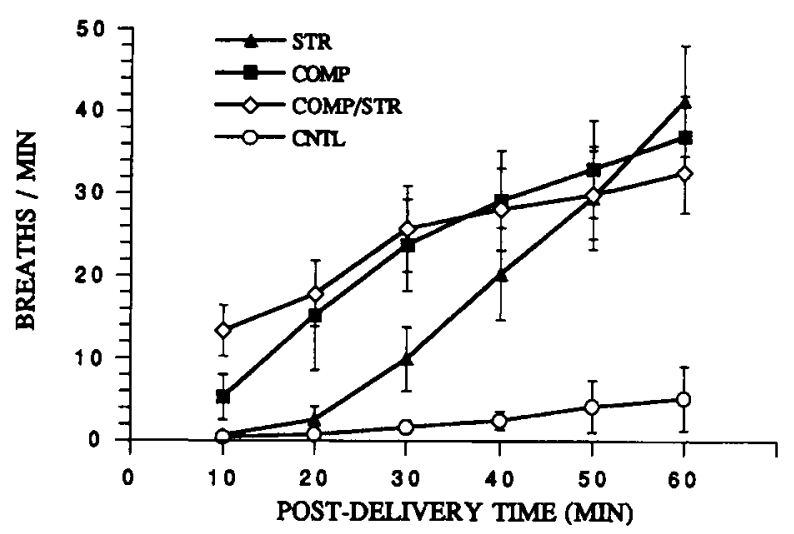

Figure 2. The average number of breaths per minute $( \pm S E)$ for neonatal rats in the STR $(n=8)$, COMP $(n=8)$, COMP/STR $(n=$ $8)$, and CNTL $(n=12)$ during the first postpartum hour. 
were similar, suggesting that these two stimuli are roughly equivalent in their ability to elicit respiratory behavior in newborn rat pups. According to these results, there was also no additive effect of simulated uterine contractions and simulated postpartum licking. Each stimulus alone is sufficient for inducing continuous, postpartum respiratory behavior. Pups in the different treatment conditions displayed different patterns of respiratory behavior early in the test. In particular, pups in the STR condition were relatively slow starters: their initial breathing frequency was significantly reduced as compared with that of pups in the other stimulus conditions, but showed a sizable increment in respiratory rate later in the test, achieving the same terminal respiratory rate as did subjects in the other experimental conditions. Importantly, terminal rates of subjects in the STR, COMP, and COMP/STR conditions were approximately 37 breaths/min, identical to those attained by pups following natural, vaginal birth (Ronca \& Alberts, 1995b). This finding provides strong support for our assertion that we have identified and made accurate reproductions of the stimuli associated with birth.

\section{EXPERIMENT 3 \\ Postpartum Survival of Cesarean Delivered Rat Pups Following Exposure to Simulated Maternal Licking}

Experiments 1 and 2 showed that cutaneous stimulation of the skin and mechanical compression of the body were equally effective in inducing respiratory behavior in fetal and newborn rats. Importantly, postpartum respiratory rates of tactilely stimulated pups closely approximate those of normal, vaginally delivered pups (see also Ronca \& Alberts, 1995b), providing strong evidence for sensory induction of breathing in newborns. However, it might be argued that, by exposing fetuses to anesthesia prior to the onset of respiratory measurement, we have created a need for the additional stimulation, which essentially acts to resuscitate the compromised newborn. Experiment 3 was conducted to determine whether unanesthetized fetuses also had sensory requirements for the induction of postpartum breathing. Pups were delivered by cesarean section, rather than by vaginal birth, in order to avoid exposure to uterine contractions and to enable delivery of controlled amounts of postpartum stimulation. Therefore, following cesarean delivery (performed with minimal handling of fetuses), stroking was applied to pups' bodies for 2 min to mimic maternal licking. The presence or absence of respiratory behavior was determined at $1 \mathrm{~h}$ postpartum.

\section{Method}

\section{Subjects}

A total of 26 rat pups were used as subjects. Breeding and maintenance were as described in Experiment 1.

\section{Cesarean-Delivery Procedure}

On GD 21 , dams were euthanized by cervical dislocation produced by pressing a rod to the base of the skull. A midline incision
$(3 \mathrm{~cm})$ was made along the lower abdomen, and a laparotomy was performed. The uterus was then incised, and fetuses in the second and third uterine positions from the ovarian end of the uterine horn were gently extracted from one horn. (Subject selection was counterbalanced across left and right horns.) Pups and their placentas, encased within the intact amniotic sac, were placed on salinesoaked gauze pads $(2 \times 2$ in.) in plastic observation cups $(5-\mathrm{cm}$ diam; Rubbermaid $\mathrm{Co}$.). Each pup's amniotic sac was gently removed, with care taken to expose the nasal passages. The umbilical cord was then occluded with a microvascular clamp and the placenta removed.

\section{General Procedure}

For the cesarean-delivered pups, members of each sibling pair were randomly assigned to one of two experimental conditions: cesarean stroke (CES-STR; $n=7$ ) or cesarean control (CES-CNTL; $n=7$ ). Pups in the CES-STR condition received 2 min of brushstroking, as described in Experiment 1. Pups in the CES-CNTL condition were treated identically to CES-STR pups except that they received no stroking. A second control group was run in which dams were permitted to deliver their pups vaginally (VAG; $n=12$ ). Two pups were taken from each litter, with each individual being removed following 2 min of postdelivery licking and handling by the dam. VAG pups were placed on saline-soaked gauze pads in observation cups, with their umbilical cords occluded and detached, if necessary. For all three conditions, observation cups were housed in a thermally controlled environment maintained at $26^{\circ} \mathrm{C}$. The presence or absence of respiratory behavior was noted $1 \mathrm{~h}$ following placement of each pup in the test environment.

\section{Results and Discussion}

Figure 3 illustrates the percentage of pups within each group that were respiring at $1 \mathrm{~h}$ postpartum. All pups in the CES-STR and VAG conditions were respiring after $1 \mathrm{~h}$; only one-fourth of pups in the CES-CNTL condition were doing so.

At the end of the test, the proportion of pups still respiring was significantly greater for the CES-STR pups than for the CES-CNTL pups $\left(\chi^{2}=14 ; p<.05\right)$. It is striking to note that the survivorship of the CES-STR and CES-CNTL pups in the present experiment was identical to that obtained for STR and CNTL subjects in Experiment 2. The high degree of consistency between the two studies was particularly surprising in light of

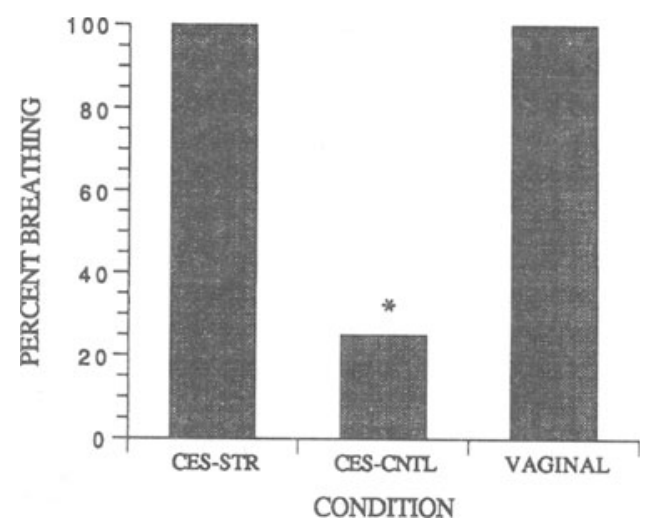

Figure 3. Percentage of CES-STR $(n=7)$, CES-CNTL $(n=7)$, and VAG $(n=14)$ pups respiring at $1 \mathrm{~h}$ postpartum. 
procedural differences: In Experiment 2, fetuses were derived from spinally transected dams, with dams and fetuses anesthetized prior to the start of experimental operations. In Experiment 3, dams were killed by cervical dislocation and pups were taken by cesarean section. The similarity in outcome obtained with these fundamentally different procedures is consistent with our observation that fetal anesthesia exposure during the maternal transection procedure exerts minimal effects on perinatal behavior and HR.

There were no differences between cesarean and vaginally delivered pups, with both groups showing a $100 \%$ survival rate. Although we did not make direct measurements of respiratory behavior, there were no observable differences between these groups in either breathing or general behavior during the first postpartum hour. These findings lend additional support to the view that afferent input, particularly cutaneous stimulation, is essential to the induction of continuous postpartum respiration.

\section{GENERAL DISCUSSION}

Prenatal and postpartum breathing are influenced by a host of physiological, behavioral, and environmental factors. The physiological status of the perinate, sensory concomitants of parturition, alterations in the fetus associated with the transition to newborn, and the conversion from an aquatic to a pneumatic environment are all relevant to the production of respiratory behavior.

In contrast to most earlier investigations, we have emphasized the role of experience in the induction of perinatal breathing. The sensory consequences of birth are nontrivial, and include stimulation of every functional modality. Perinatal rats are characterized by immature sensory status, with only a subset of senses (viz., tactile, vestibular, thermal, and chemical modalities) sufficiently operative to transduce sensory information. In the present study, we measured respiratory behavior to a single sensory component of the birth process: cutaneous stimulation mimicking maternal licking of pups. Dams spend an average of 2 min licking neonates as they emerge from the birth canal, often removing the pup's amniotic encasement (Ronca et al., 1993). Because it provides the newborn with access to air, sac removal is an important consequence of the dam's postpartum licking. Nevertheless, the present findings emphasize that sensory input is equally critical for the induction of perinatal respiratory behavior.

\section{Prenatal Respiratory Behavior}

Fetuses with the amniotic sac removed and exposed to a heated air environment showed occasional respiratory movements; their average respiratory rate never exceeded 5 breaths/min, while the peak rate for stroked pups was 15 breaths/min (Figure 1). Interestingly, breathing rates of nonstimulated pups exposed to air exactly match the medullary respiratory rhythm measured in Day 21 fetal rats (Di Pasquale, Monteau, \& Hilaire, 1994). Despite the relatively modest amount of cutaneous stim- ulation applied to subjects in the present study, fetal breathing rates remained elevated throughout the test. It is noteworthy that the elevated breathing rates displayed by stroked fetuses in this study are comparable to those observed in compressed fetuses in our previous work (Ronca \& Alberts, 1995b). In the first case, $120 \mathrm{sec}$ of stimulation was delivered in $120 \mathrm{sec}$, and in the second case, $300 \mathrm{sec}$ of stimulation was delivered over a time span of 900 sec.

Although it is not possible to directly compare the strengths of the compressive and stroke stimuli, it is impressive that a relatively brief episode of concentrated cutaneous stimulation produced by stroking had such a dramatic and long-lasting effect on fetal behavior. It appears that tactile input may trigger persistent, even permanent, alterations of physiology and behavior, particularly those that comprise the transition to air-breathing. Somatosensory recruitment of brainstem respiratory centers may elicit short-term increases in respiratory behavior which, in the presence of air, may set in motion pulmonary mechanical transformations relevant to postnatal adaptation, including absorption of fetal lung liquid, reduction of pulmonary vascular resistance, elevation of pulmonary blood flow, and the establishment of alveolar-capillary gas exchange (Scarpelli, 1990). It remains to be determined whether the same facilitatory effect would be observed within the aquatic environment of the uterus.

Prenatal respiratory movements serve several functions during fetal development. Fetal breathing is important for adequate early pulmonary development (Liggins, 1982). High cervical cordotomy, which eliminates fetal breathing movements, results in pulmonary hypoplasia (Liggins, Vilos, Campos, Kitterman, \& Lee, 1981; Wiggleworth \& Desai, 1979), as does curare-induced paralysis (Moessinger, 1983) and maternal ingestion of alcohol (Inselman, Fisher, Spencer, \& Atkinson, 1985). The latter are both interventions that reduce or eliminate fetal breathing. Lung hypoplasia is also prevalent in anencephaly and other clinical conditions in which fetal breathing is infrequent (Kitterman, 1986; Visser, Laurini, deVries, Bekedam, \& Prechtl, 1985). Fetal breathing significantly increases fetal cardiac output and blood flow to a number of vital organs, including heart, brain, and placenta (Jansen, Belik, Ioffe, \& Chernick, 1989), suggesting an important role in distribution of the cardiac output, a function which may (indirectly) facilitate organ development (Jansen \& Chernick, 1991).

Fetal respiratory movements, as well as body, limb, and eye movements, tend to become grouped into episodes that correlate with low-voltage, high-frequency electrocorticogram (EcOG) waveforms (Moore \& Hanson, 1992). Increased blood flow to brain and augmented cerebral oxidative metabolism reportedly coincide with this EcOG pattern (Richardson, Carmichael, Homan, \& Gagnon, 1989). Extrinsic stimulation can elicit a change in fetal state. For example, Parkes, Moore, Moore, Fisk, and Hanson (1991) found that an auditory stimulus applied to the maternal flank in sheep caused a transition 
in fetal ECoG from the high- to low-voltage waveform that was associated with increased breathing and eye movements. A growing body of evidence suggests that significant amounts of afferent input are available to, and can be detected by, the fetus in utero (for reviews, see Fifer \& Moon, 1995; Ronca \& Alberts, 1995a). For instance, low-intensity contractions that antedate labor, termed "Braxton-Hicks" contractions (Page, Villee, \& Villee, 1981) or "contractures" (Nathanielsz et al., 1985), occur regularly during the second half of gestation. Compressive and/or cutaneous stimulation associated with contractile activity prior to labor may arouse the fetus and thereby elicit breathing and other movements. In other words, contractile activity of uterine tissue may provide an important source of stimulation for breathing "practice" before birth.

\section{Postpartum Respiratory Behavior}

The onset of continuous breathing in newborn mammals is not well understood (Lagercrantz, 1991). The idea that a placental inhibitory factor exists which depresses prenatal breathing but is eliminated from the circulation at birth has garnered some support: studies of fetal sheep oxygenated in utero have shown that umbilicalcord occlusion alone induces continuous breathing and arousal (Baier et al., 1992). Administration of a placental extract containing the prostaglandin inhibitor eliminated continuous breathing (Alvaro et al., 1993). However, the unanesthetized fetal sheep model may be somewhat limited in its ability to reveal the actual events leading to the onset of continuous postpartum respiration (Adamson et al., 1991; Ronca \& Alberts, 1995b). The most apparent limitation is that the fetal sheep's lungs are artificially distended and ventilated with oxygen, whereas in nature the newborn must displace lung fluid to permit the entry of air.

Newborn rats in our studies did not survive umbilicalcord occlusion alone. Rather, the onset of sustained breathing, at rates comparable to those of naturally born pups, required the biological events that normally accompany the birth process. Without birth-related stimulation, only a small proportion of pups successfully completed the transition to continuous postpartum breathing. It is important to note that the mere presence of breathing (albeit, episodic breathing) in nonstroked pups early in the measurement interval did not ensure postpartum survival. Perhaps respiratory behavior must reach a frequency threshold or must persist for sufficient time to clear the placental inhibitor from the fetal circulation. Sensory input may provide the first link in this postpartum chain. According to this hypothesis, birth stimulation would reduce the concentration of inhibitory prostaglandins, thereby enabling the onset of breathing. Without the increment in breathing rate induced by stimulation, the basal rate is not sufficient to clear prostaglandins from the fetal circulation. In support of this view, the respiratory rate of stimulated fetuses in our study increased progressively over the first postpartum hour. Thus, while the elimination of a placental inhibitory agent is likely to be an important factor in the onset of postpartum breathing, mere occlusion of the umbilical cord may not be sufficient for its clearing from the fetal circulation and, therefore, for sustained postpartum breathing.

Cutaneous stimulation may also elicit release of central and/or adrenal medullary catecholamines in the fetus and newborn. Plasma catecholamines have been shown to surge at birth in newborn infants (Lagercrantz \& Bistoletti, 1977). Moreover, infants delivered by elective cesarean section have low catecholamine levels, as compared with infants delivered after labor has begun or with vaginally delivered infants (Lagercrantz \& Slotkin, 1986). We have proposed that somatosensory stimulation of the fetus associated with labor contractions may contribute to elevated catecholamine concentrations in newborns (Ronca \& Alberts, 1995b).

In summary, our findings show that sensory stimulation provides the necessary and sufficient conditions for initiating sustained, postpartum respiratory behavior. It is not known at this time whether our findings are specific to somatosensory afferent stimulation or if they represent an adaptive behavioral response to sensory input in general.

\section{Organizational Effects of Maternal Stimulation on Infant Behavior and Physiology}

There is a growing literature on the organizational effects of maternal stimulation on infant behavior and physiology. The neonate possesses few totally independent regulations, and relies on stimulation from the mother for induction and maintenance of normal behavior and physiology (Hofer, 1983). In this regard, physical stimulation appears to have particular biological relevance. Stroking alters basic biological processes of infant rats, including ornithine decarboxylase levels in brain, heart, and liver (Butler, Suskind, \& Schanberg, 1968; Evoniuk, Kuhn, \& Schanberg, 1979; Kuhn, Butler, \& Schanberg, 1978), and in adrenocortical activity (Smotherman, 1983; Stanton \& Levine, 1984), heart rate (Hofer, 1983; Hofer \& Winer, 1975), and blood pressure (Shear et al., 1983). Physical stimulation reduces pup body and brain temperatures by increasing ventilatory heat exchange, a manuever which, in turn, increases convective and evaporative heat loss (Sullivan, Shokrai, \& Leon, 1988; Sullivan, Wilson, \& Leon, 1988). Pups require licking and other maternally produced stimuli for recruitment of this physiological thermoregulatory system.

The bulk of evidence indicates that the effects of physical stimulation are nonspecific. Stroking (Pedersen \& Blass, 1982; Pedersen, Williams, \& Blass, 1982), amphetamine injection (Pederson et al., 1982), milk infusion (Johanson \& Hall, 1982), electrical stimulation of the MFB (Moran, Lew, \& Blass, 1981), the odor of maternal saliva, and tailpinch (Sullivan, Brake, Hofer, \& Williams, 1986) have all been reported to activate pups and, in some cases, enhance formation of olfactory-based pref- 
erences. This diverse array of stimuli may tap into a common reinforcement mechanism, of which behavioral activation is one component (Hall, 1987; Sullivan \& Hall, 1988). Since activation is correlated with increased respiratory behavior (Alberts \& May, 1980; Pedersen \& Blass, 1982; Sullivan, Shokrai, \& Leon, 1988; Sullivan, Wilson, \& Leon, 1988), other forms of maternally derived stimuli may contribute to the onset of continuous breathing at birth. We look forward to testing this hypothesis in future studies. In any case, our results demonstrate powerful effects of cutaneous stimulation on fetal and neonatal respiratory behavior, and support the view that perinatal sensory experience is a critical link in the chain of adaptive adjustments required for the fetus's transition to newborn.

\section{REFERENCES}

Adamson, S. L., Kuipers, I. M., \& Olsen, D. M. (1991). Umbilical cord occlusion stimulates breathing independent of blood gases and pH. Journal of Applied Physiology, 70, 1796-1809.

ALberTs, J. R., \& MAY, B. (1980). Development of nasal respiration and sniffing in the rat. Physiology \& Behavior, 24, 957-963.

Alberts, J. R., \& RonCA, A. E. (1993). Fetal experience revealed by rats: Psychobiological insights. Early Human Development, 35, 153166

Alvaro, R., De-Almeida, V., Al-Alaiyan, S., Robertson, M., Nowaczyk, B., Cates, D., \& Rigatto, H. (1993). A placental extract inhibits breathing induced by umbilical cord occlusion in fetal sheep. Journal of Developmental Physiology, 19, 23-28.

Baier, R. J., Hasan, S. U., Cates, D. B., Hooper, D., Nowaczyk, B., \& RigaTTO, H. (1992). Effects of various concentrations of $\mathrm{O}_{2}$ and umbilical cord occlusion on fetal breathing and behavior. Journal of Applied Physiology, 68, 1597-1604.

Bradley, R. M., \& Mistretta, C. M. (1975). Fetal sensory receptors. Physiological Reviews, 55, 352-382.

Butler, S. R., Suskind, M. R., \& Schanberg, S. M. (1968). Maternal behavior as a regulator of polyamine synthesis in brain and heart of the developing rat pup. Science, 199, 445-447.

CONDORELli, S., \& SCARPELli, E. M. (1975). Somatic respiratory reflex and onset of regular breathing movements in the lamb fetus in utero. Pediatric Research, 9, 879-884.

DAWES, G. S. (1968). Fetal and neonatal physiology. Chicago: Year Book Medical Publishers.

DAwES, G. S. (1974). Breathing before birth in animals and man. New England Journal of Medicine, 290, 557-559.

DeCASPER, A. J., \& FifER, W. P. (1980). Of human bonding: Newborns prefer their mothers' voices. Science, 208, 1174-1176.

Di Pasquale, E., Monteau, R., \& Hilaire, G. (1994). Involvement of the rostral ventro-lateral medulla in respiratory rhythm genesis during the perinatal period: An in-vitro study in newborn and fetal rats. Developmental Brain Research, 78, 243-252.

Evoniuk, G. E., Kuhn, C. M., \& Schanberg, S. M. (1979). The effect of tactile stimulation on serum growth hormone and tissue ornithine decarboxylase activity during maternal deprivation in rat pups. Communications in Psychopharmacology, 3, 363-370.

FIFER, W. P., \& MOON, C. M. (1988). Auditory experience in the fetus. In W. P. Smotherman \& S. R. Robinson (Eds.), Behavior of the fetus (pp. 175-188). Caldwell, NJ: Telford Press.

FIFER, W. P., \& Moon, C. M. (1995). The effects of fetal experience with sound. In J.-P. Lecanuet, W. Fifer, W. P. Smotherman, \& N. A. Krasnegor (Eds.), Fetal development: A psychobiological perspective (pp. 351-366). Hillsdale, NJ: Erlbaum.

FUCHS, A.-R. (1969). Uterine activity in late pregnancy and during parturition in the rat. Biology of Reproduction, 1, 344-353.

FuCHS, A.-R. (1979). Hormonal control of myometrial function during pregnancy and parturition. Acta Endocrinologica, 221, 1-70.
GerhaRd, K. J. (1989). Characteristics of the fetal sheep sound environment. Seminars in Perinatology, 13, 362-370.

Gluckman, P. D., Gunn, T. R., \& Johnston, B. M. (1983). The effects of cooling on breathing and shivering in unanaesthetized fetal lamb in utero. Journal of Physiology, 343, 495-506.

HaLL, W. G. (1987). Early motivation, reward, learning, and their neural bases: Developmental revelations and implications. In N. A Krasnegor, E. M. Blass, M. A. Hofer, \& W. P. Smotherman (Eds.), Perinatal development: A psychobiological perspective (pp. 169. 193). Orlando, FL: Academic Press.

HOFER, M. A. (1981). The roots of human behavior: An introduction to the psychobiology of early human development. San Francisco: W. H. Freeman.

HofER, M. A. (1983). The mother-infant interaction as a regulator of infant physiology and behavior. In A. Rosenblum \& H. Moltz (Eds.), Symbiosis in parent-offspring interactions (pp. 61-75). New York: Plenum.

Hofer, M. A., \& ShaIR, H. (1982). Control of sleep-wake states in the infant rat by features of the mother-infant relationship. Developmental Psychobiology, 15, 229-244.

HOFER, M. A., \& WINER, H. (1975). Physiological mechanisms for cardiac control by nutritional intake after early maternal separation in young rats. Psychosomatic Medicine, 42, 513-520.

InSElman, L. S., Fisher, S. E., Spencer, H., \& Atkinson, M. (1985). Effect of intrauterine ethanol exposure on fetal lung growth. Pediatric Research, 19, 12-14.

J ANSEN, A. H., Belik, J., IOFFe, S., \& CheRnick, V. (1989). Control of organ blood flow in sheep during normoxia and hypoxia. American Journal of Physiology, 257 [Heart Circulation Physiology, 26], H1132-H1139.

Jansen, A. H., \& Chernick, V. (1991). Fetal breathing and development of control of breathing. Journal of Applied Physiology, 70, 1431-1446.

Johanson, I. B., \& HaLL, W. G. (1982). Appetitive conditioning in neonatal rats: Conditioned orientation to an odor. Developmental Psychobiology, 15, 379-397.

Kitterman, J. A. (1986). Physical factors and fetal lung growth. In B. M. Johnston \& P. D. Gluckman (Eds.), Respiratory control and lung development in the fetus and newborn (pp. 63-85). Ithaca, NY: Perinatology Press.

Kuhn, C. M., Butler, S. R., \& Schanberg, S. M. (1978). Selective depression of serum growth hormone during maternal deprivation in rats. Science, 201, 1034-1036.

Kuhn, C. M., Schanberg, S. M., Field, T. M., Symanski, R., ZimMerman, E., Scafidi, F., \& Roberts, J. (1991). Tactile-kinesthetic stimulation effects on sympathetic and adrenocortical function in preterm infants. Journal of Pediatrics, 119, 434-440.

LAGERCRANTZ, H. (1991). Respiratory control and stimulation of spontaneous breathing. International Journal of Technology Assessment in Health Care, 7 (Suppl. 1), 47-51.

Lagercrantz, H., \& Bistoletti, P. (1977). Catecholamine release in the newborn. Pediatric Research, 11, 889-893.

Lagercrantz, H., \& Slotkin, T. (1986). The "stress" of being born. Scientific American, 254, 100-107.

LAMBertson, C. J. (1974). Physical and mechanical aspects of respiration. In V. B. Mountcastle (Ed.), Medical physiology (Vol. 2, pp. 1361-1371). St. Louis: Mosby.

LigGins, G. C. (1982). The fetus and birth. In C. R. Austin \& R. V. Short (Eds.), Reproduction in mammals (pp. 114-141). New York: Cambridge University Press.

Liggins, G. C., Vilos, G. A., Campos, G. A., Kitterman, J. A., \& LeE, C. H. (1981). The effect of spinal cord transection on lung development in fetal sheep. Journal of Developmental Physiology, 3, 267274

Moessinger, A. C. (1983). Fetal akinesia deformation sequence: An animal model. Pediatrics, 72, 857-863.

MOORE, P. J., \& HaNSON, M. A. (1992). Animal investigations. In J. G. Nihjuis (Ed.), Fetal behavior. Oxford: Oxford Medical Publications.

Moran, T. H., LEW, M. F., \& Blass, E. M. (1981). Intracranial selfstimulation in 3-day-old rat pups. Science, 214, 1366-1368.

Narayanan, C. H., Fox, M. W., \& Hamburger, V. (1971). Prenatal de- 
velopment of spontaneous and evoked activity in the rat. Behavior, 40, 100-134.

Nathanielsz, P. W., Figueroa, J. P., El Badry, A., Sunderj, S., Frank, D. A., Pimental, G., Poore, E. R., \& Mitchell, M. D. (1985). Myometrial activity: Control and effects. In C. T. Jones \& P. W. Nathanielsz (Eds.), The physiological development of the fetus (pp. 355-362). London: Academic Press

Olver, R. E. (1981). Of labour and the lungs. Archives of Disease in Childhood, 56, 659-662.

Page, E. W., Villee, C. A., \& Villee, D. B. (1981). Human reproduction: Essentials of reproductive and perinatal medicine. Philadelphia: W. B. Saunders.

Parkes, M. J., Moore, P. J., Moore, D. R., Fisk, N. M., \& Hanson, M. A. (1991). Behavioral changes in fetal sheep caused by vibroacoustic stimulation: The effects of cochlear ablation. American Journal of Obstetrics \& Gynecology, 164, 1336-1343.

Pedersen, P. E., \& Blass, E. M. ( 1982). Prenatal and postnatal determinants of the 1 st suckling episode in albino rats. Developmental Psychobiology, 15, 349-355.

Pedersen, P. E., Williams, C. L., \& Blass, E. M. (1982). Activation and odor conditioning of suckling behavior in 3-day-old albino rats. Journal of Experimental Psychology: Animal Behavior Processes, 8. 829-841.

Richardson, B. S., Carmichael, L., homan, J., \& Gagnon, R. (1989). Cerebral oxidative metabolism in lambs during the perinatal period: Relationship to electrocortical state. American Journal of Physiology, 257, R1251-R1257.

RonCA, A. E., \& AlberTS, J. R. (1994). Sensory stimuli associated with gestation and parturition evoke cardiac and behavioral responses in fetal rats. Psychobiology, 22, 270-282.

RonCA, A. E., \& AlBerTs, J. R. (1995a). Maternal contributions to fetal experience and the transition from prenatal to postnatal life. In J.-P. Lecanuet, W. Fifer, W. P. Smotherman, \& N. A. Krasnegor (Eds.), Fetal development: A psychobiological perspective (pp. 330350). Hillsdale, NJ: Erlbaum.

RoncA, A. E., \& Alberts, J. R. (1995b). Simulated uterine contractions facilitate respiratory behavior in fetal and newborn rats. Physiology \& Behavior, 5, 1035-1041.

Ronca, A. E., Lamkin, C. A., \& Alberts, J. R. (1993). Maternal contributions to sensory experience in the fetal and newborn rat (Rattus norvegicus). Journal of Comparative Psychology, 107, 61-74.

Ronca, A. E., Smotherman, W. P., Robinson, S. R., \& Al.berts, J. R. (1987, November). Chemosensory and tactile stimuli elicit heart rate and motor responses in the rat fetus. Paper presented at the meeting of the International Society for Developmental Psychobiology, New Orleans.

Rosenblatt, J. S., \& Lehrman, D. S. (1967). Maternal behavior in the laboratory rat. In H. L. Rheingold (Ed.), Maternal hehavior in mammals (pp. 8-57). New York: Wiley.

SCARPELLI, E. M. (1990). Micromechanics of the onset of air-breathing at birth. In E. M. Scarpelli (Ed.), Pulmonary physiology: Fetus, newborn, child, and adolescent. Philadelphia: Lea \& Febiger.
Scarpelli, E. M., Condorelli, S., \& Cosmi, E. V. (1977). Cutaneous stimulation and the generation of breathing in the fetus. Pediatric Research, 11, 24-28.

SchaAl, B., \& Orgeur, P. (1992). Olfaction in utero: Can the rodent model be generalized? Quarterly Journal of Experimental Psychology, 44B, 245-278.

Shear, W. K., Brunelli, S. A., \& Hofer, M. A. (1983). The effects of maternal deprivation and of refeeding on the blood pressure of infant rats. Psychosomatic Medicine, 31, 372-388.

Smotherman, W. P. (1983). Mother-infant interaction and modulation of pituitary-adrenal activity in rat pups after early stimulation. Developmental Psychobiology, 16, 169-176.

Smotherman, W. P., Richards, L. S., \& Robinson, S. R. (1984). Techniques for observing fetal behavior in utero: A comparison of chemomyelotomy and spinal transection. Developmental Psychobiology, $17,661-674$.

Smotherman, W. P., \& Robinson, S. R. (1988). The uterus as environment: The ecology of fetal behavior. In E. M. Blass (Ed.), Handbook of behavioral neuroscience (Vol. 9, pp. 1-39). New York: Plenum.

Stanton, M. E., \& Levine, S. (1984). Maternal contact inhibits pituitary-adrenal activity in preweanling rats. Society for Neuroscience Abstracts, 10,86.

Sullivan, R. M., Brake, S. C., Hofer, M. A., \& Williams, C. L. (1986). Huddling and independent feeding of neonatal rats can be facilitated by a conditioned change in behavioral state. Developmental Psychobiology, 19, 625-635.

Sullivan, R. M., \& HALL, W. G. (1988). Reinforcers in infancy: Classical conditioning using stroking or intraoral infusions of milk as UCS. Developmental Psychobiology, 21, 215-224.

Sullivan, R. M., Shokral, N., \& Leon, M. (1988). Physical stimulation reduces the body temperature of infant rats. Developmental Psychobiologv, 21, 225-236.

Sullivan, R. M., Wilson, D. A., \& Leon, M. (1988). Physical stimulation reduces the brain temperature of infant rats. Developmental Psychobiology, 21, 237-250.

Vince, M. A., Billing, B. A., Baldwin, B. A., Toner, J. N., \& WELLER, C. (1985). Maternal vocalisations and other sound in the fetal lamb's sound environment. Early Human Development, 11, $179-190$

Visser, G. H., Laurini, R. N., deVries, J. I. P., Bekedam, D. J., \& PRECHTL, H. F. R. (1985). Abnormal motor behavior in anencephalic fetuses. Early Human Development, 12, 173-182.

WigGlewORTH, J. S., \& DESAi, R. (1979). Effects on lung growth of cervical cord section in the rabbit fetus. Early Human Development, $3,51-65$.

(Manuscript received June I, 1995; revision accepted for publication August 16, 1995.) 